\title{
Future of Interactive Architecture in Developing Countries: Challenges and Opportunities in Case of Tehran
}

\author{
Masoome Amini, "Mohammadjavad Mahdavinejad and \\ Mohammadreza Bemanian
}

Published online: 30 August 2019

To cite this article: Masoome Amini, Mohammadjavad Mahdavinejad and Mohammadreza Bemanian (2019). Future of interactive architecture in developing countries: Challenges and opportunities in case of Tehran. Journal of Construction in Developing Countries, 24(1): 163-184. https://doi.org/10.21315/jcdc2019.24.1.9.

To link to this article: https://doi.org/10.21315/jcdc2019.24.1.9

\begin{abstract}
In today's world, interactive architecture is a process-oriented guide to creating dynamic spaces capable of performing a range of pragmatic and humanistic functions. While this architecture is evolving rapidly, its implementation in some developing countries is not very feasible. Iran is one of the developing countries that is seeking to learn more about use of new technologies in the construction industry to create new ideas for the future of architecture. Tehran as the capital of Iran has the proper capacities for implementing interactive architecture. Due to the main focus of the research on the future of interactive technologies in Tehran and to benefit from expert views, the Delphi method was used to collect the required information. According to the new concept of interactive architecture in Tehran, purposeful sampling was applied and only experts who have sufficient expertise in both interactive architecture and contemporary Iranian architecture were selected to respond. After collecting the responses in the questionnaire, they were converted to numerical scales to analyse the impact of the different factors in the future of Tehran's architecture. Results show that in Tehran, in the three main areas of technology, economy and culture, constraints exist for the implementation of real interactive architecture.
\end{abstract}

Keywords: Interactive architecture, Iranian architecture, New technologies, Developing countries, Tehran

\section{INTRODUCTION}

Contemporary architecture should discover the hidden potential of traditional architecture and use new technologies and strategies to create a novel architectural identity for the future. It is time to stop asking what architecture is and start asking what it can do. Interactive architecture is a processes-oriented guide to creating dynamic spaces and objects capable of performing a range of pragmatic and humanistic functions (Fox, 2016). These complex physical interactions are made possible by the creative fusion of embedded computation (intelligence) with a physical, tangible counterpart (kinetics).

Interactive architecture outlines a vision for the future through contextualising and understanding the current landscape of projects and trends in its domain, and its integration of new emerging technologies (Fox and Kemp, 2009). This architecture includes contributions from the worlds of architecture, industrial design, computer programming, engineering and physical computing (Fox, 2016). In other words,

Faculty of Art and Architecture, Tarbiat Modares University, Tehran, IRAN

"Corresponding author: mahdavinejad@modares.ac.ir 
interactive architecture is not only perceived as a product, but also as a process (Figure 1).
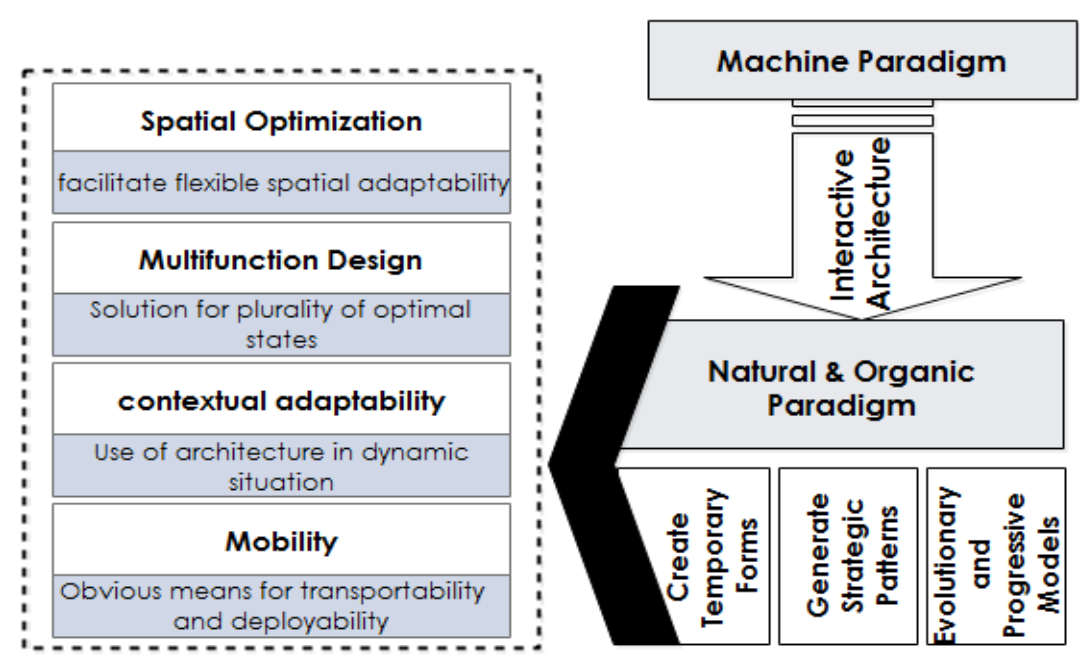

Figure 1. Definition of Interactive Architecture Based on Its Applications in Space

Interactive architecture is not simply architecture that is responsive or adaptive to changing circumstances. On the contrary, this architecture is based on the concept of bi-directional communication, which requires two active parties. Interactive architecture is not about communication between people; it is first defined as the art of building relationships between the built components and second, as that of building relations between people and those components (Oosterhuis, 2013). As Usman Haque puts it, a truly interactive system is a multipleloop system in which one enters into a conversation: a continual and constructive information exchange. As people interact with architecture, they should not be thought of as "users" but instead as "participants" (Haque, 2006). Therefore, this architecture has no stable static configuration (as shown in Figure 2).

In interactive architecture, the perceptual boundaries between the virtual and physical worlds have been broken and the question is how architecture and its tasks can creatively adopt a fourth dimension, that of digital technologies (Bullivant, 2005). This theory means that interactive architecture, rather than responding to pre-planned conditions, is able to maintain a continuous conversation not only with its users, but also among its components as presented in Table 1. 

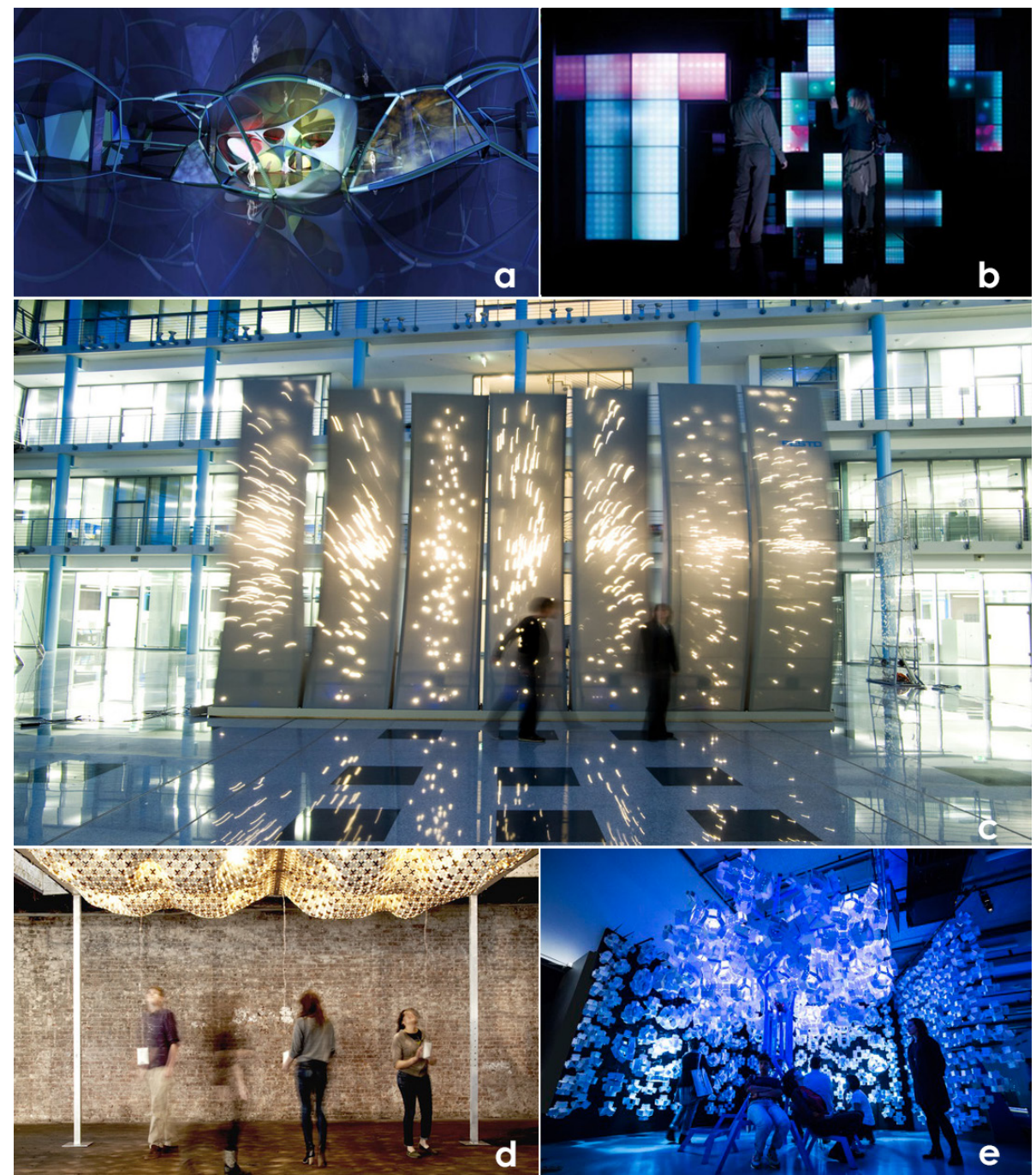

Note: Coloured version of this figure is available in the online edition of Journal of Construction in Developing Countries

Figure 2. Examples of Interactive Architecture in the World, from: (a) Lénárd and Oosterhuis (2006), (b) Oosterhuis and Lénárd (2007), (c) Hosale and Kievid (2009)

(d) Drumm (2012) and (e) Abramovic and Glynn (2018) 
Table 1. Overview and Background of Interactive Architecture

\begin{tabular}{ll}
\hline Years & $\begin{array}{l}\text { Effective Events in the Process of the Evolution and Formation of } \\
\text { Interactive Architecture }\end{array}$ \\
\hline $1960 \mathrm{~s}$ & $\begin{array}{l}\text { 1. Formulating existing theories, principles and fields of interactive } \\
\text { architecture formulated by Gordon Pask and other cyberneticists. }\end{array}$ \\
2. Cedric Price designed the Fun Palace Model and presented the \\
concept of anticipatory architecture that was indeterminate, \\
responsive and flexible for people's changing needs and their \\
times. \\
1970s
\end{tabular}

Source: Fox and Kemp (2009), Lee (1983) and Riley (2002)

\section{LITERATURE REVIEW}

\section{The Functional Nature of Interactive Architecture}

The integration of motion into the built environment, and its impact upon the aesthetics, design and performance of buildings, may be of great importance to the field of architecture (Terzidis, 2003). While the aesthetic value of virtual motion may always be a source of inspiration, its physical implementation in buildings and structures may challenge the very nature of what architecture really is (Kronenburg, 2003). New technologies and computer science can be mentioned as the main material of interactive architecture. Though it has now come to refer to anything generally reactive or responsive, a few decades ago interactive described a very different concept. By obscuring the distinction between interactive and reactive we lose a potentially fertile conceptual framework (Haque, 2007) (refer Figure 3). 


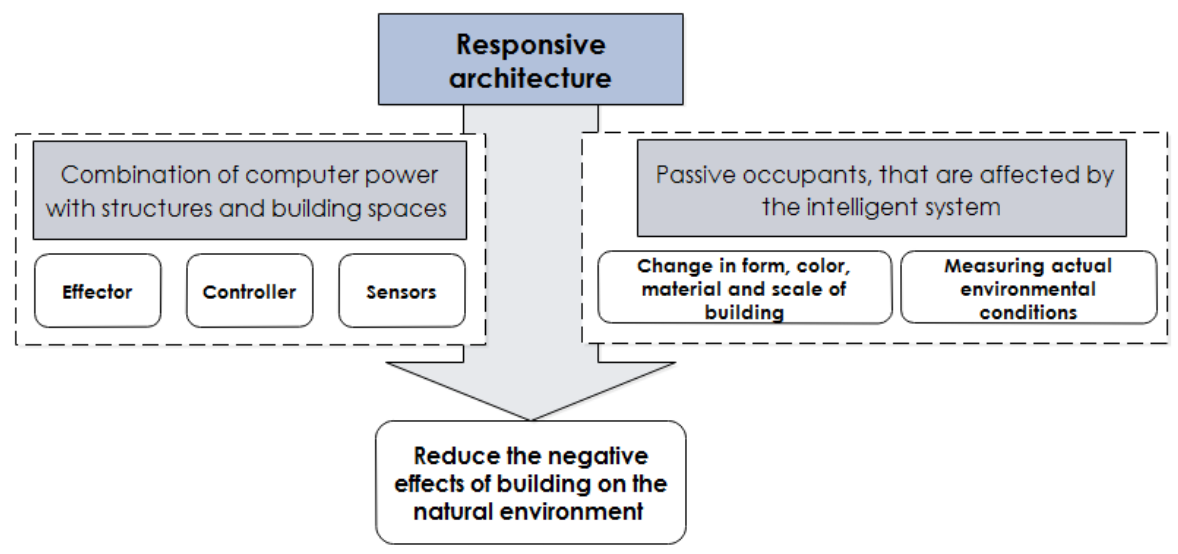

Figure 3. The Functional Nature of Responsive Architecture Based on Its Features

Interactive architecture creates new architectural solutions with a combination of new technologies and dynamic approaches to past perspectives. The driving forces in new technologies affect the changing patterns of human interaction with the environment (Edmondson, 2001). In addition, this architecture can be discussed in fields of sustainable development. The main purpose of sustainable development is to provide the basic requirements, enhance and improve the level of living for all and make a secure and blissful future (Keniger et al., 2013; Parsaee, Motealleh and Parva, 2016).

Generally, responsive architectures as part of interactive architecture are those that measure actual environmental conditions (via sensors) to enable buildings to adapt their form, shape, colour or character responsively (via actuators) (Beesley, 2006). Responsive buildings enable a physical response to changes in the environment through specific building elements (Meagher, 2015). In other words, the goal of this architecture is to reduce the negative effects of building construction on the natural environment (Butcher, 2006). This architecture is the natural product of the combination of computer power with structures and building spaces.

Interactive architecture distinguishes itself from prescribed or responsive environments through its ability to create real-time, personalised conversations with its visitors (Jaskiewicz, Aprile and van der Helm, 2010). Whether explicitly through a digital interface or implicitly through smart sensors, the visitors initiate communication. Then, as good conversations usually go, the data are absorbed, processed, and transformed to deliver newly curated information (Chen, 2015). Such architecture demands intelligence. That kind of intelligence requires two elements: data storage and some sort of data processing capacity. The former serves as a memory, the latter as processing. Only the digital can facilitate these types of conversations (Krakowsky, 2008). Contrary to popular belief, interactive architecture has a concept beyond the visible body and can include criteria such as aesthetics or complex economic and social values. This architecture as a place which directs human behaviour must meet a variety of individual and collective needs. 
Originally, a truly interactive system is a multiple-loop system in which one enters into a conversation: a continual and constructive information exchange (Haque, 2006). As people interact with architecture, they should not be thought of as "users" but instead as "participants". Marcos Novak uses the term "transactive intelligence" to define an architectural intelligence that not only interacts, but that transacts and transforms both the user and itself (Camile, 2005). Interactive architecture is not only responsive, adaptable, but is also based on the concept of multifaceted communication as featured in Figure 4.

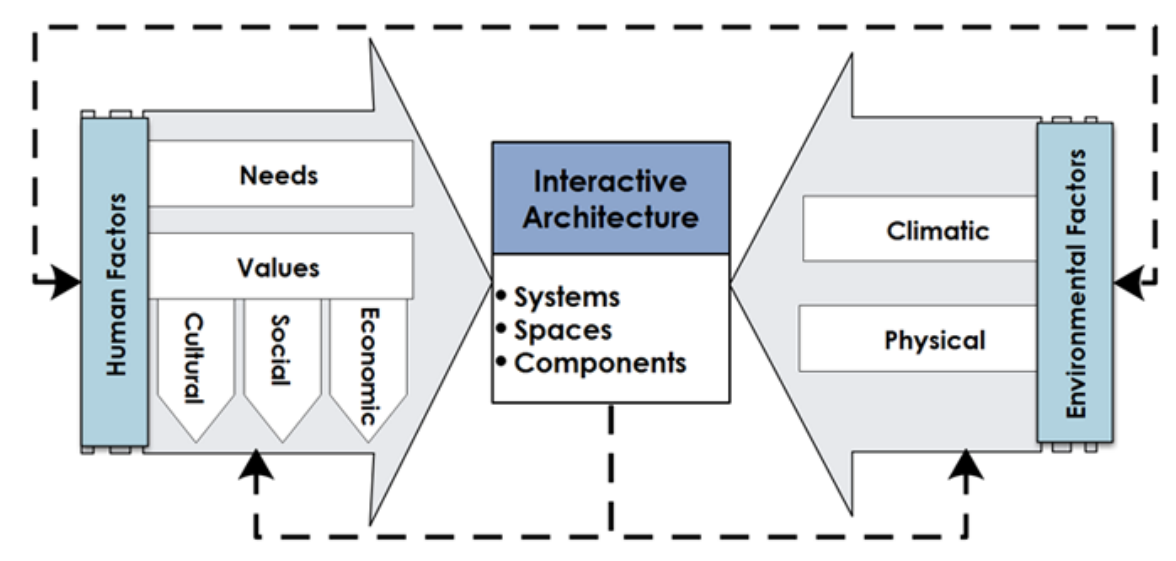

Figure 4. The Functional Nature of Interactive Architecture

Real interactive architecture entails learning to articulate the dynamic possibilities of built form and learning to think how an architectural environment can be empowered to adapt in a way that goes beyond a mere capacity to adapt. The motivation to make interactive systems is found in the desire to create spaces and objects that can meet changing needs with respect to evolving individual, social, and environmental demands (Fox and Kemp, 2009). In this architecture, shape, texture, colour, transparency and other material properties are gradually changing (Fox, 2016). Interactive architecture is not a product-oriented architecture, but a process-oriented architecture in which form is defined by the dynamic behaviour and needs of its users and the changing internal and external conditions.

\section{Iranian contemporary architecture}

Since the beginning of the 20th century, Iran has witnessed great social, economic, and cultural changes that have influenced different aspects of Iranian life. Architecture, as the physical embodiment of social life, has changed to a great extent. The architecture of the transitional and contemporary periods saw the emergence of different styles, depending on new building technologies and various other influences (Mirmoghtadaee, 2009). In fact, the concept of modernisation implies changing social thinking patterns and values (Ghobadian, 2013). Contemporary Iranian architecture is looking for a new intellectual orientation and evolution in order to promote the country's architecture (Bani Masoud, 2011), which it requires to create a platform for the implementation of high-tech projects. 
In Iranian architecture over the last 100 years, on the one hand, the traditional values in architecture cannot be ignored; on the other hand, the transfer of Western architecture to Iran and especially the presence of the modern style in the late Pahlavi era, increased the pace of developments in the field of architecture and urbanisation (Ghobadian, 2013). But all these developments, whether wanted or unwanted, created change in architecture and urbanisation and revealed characteristics that have each been an important factor for the development of Iranian architecture in contemporary times (Kiani, Behjou and Tehrani, 2016; Mahdavinejad et al., 2014). In this regard, it is obvious that a proper understanding of contemporary Iranian architecture can have a positive impact on its future.

\section{INTERACTIVE ARCHITECTURE AND DEVELOPING COUNTRIES}

As Reyner Banham has argued: architecture and technology cannot be separated (Abrahamson, 2009). As the latter has advanced and as computers have become smaller and cheaper, we are seeing that we now have the potential to think of space as being organised in a computational network (Greenfield, 2010). The initiation of computational design means architects can pursue new frontiers where architecture can be generated through the writing of algorithms and software and where interactive physical mechanisms that respond to their environment, adapting and evolving as necessary, can be built (Peters, 2013). Therefore, the rapid progress of technology is a useful tool for architects, enabling them to create sophisticated buildings that respond to the needs of users.

The reason behind this interactive movement is not just to use the technology that happens to be available to us, but to create environments that adapt and evolve to be simply the best and most beautiful in any given moment (Prelovsek, 2017). Interactive architecture has been designed to create environments and buildings that respond to changing needs, respect the social and environmental demands of inhabitants (Fox and Kemp, 2009; Jaskiewicz, 2013) and finally, raise the standard of their living and ultimately design structures which could satisfy them.

According to authors such as Walt Whitman Rostow, developing countries are in transition from traditional lifestyles towards the modern lifestyle (Rostow, 1984). One of the development indicators, from the perspective of the World Bank, is the use of new technologies. This technological advancement can occur in various areas one of the most important fields of which is architecture and construction (Mahdavinejad, Rafsanjani and Karimi, 2013). Accordingly, understanding interactive architecture as one of the newest methods in design can be a basic step in development.

In developing countries, advancement will only be achieved when interactive architecture's systems are addressed as an integral part of a larger vision that takes advantage of today's pervasive, constantly unfolding, and farreaching technologies (Fox and Kemp, 2009). Prediction for the future of interactive architecture in developing countries is somewhat hard, but it should be noted that interactive systems in buildings will inevitably be part of future architecture. Therefore, research on the conditions for the realisation of such systems in these countries is highly necessary. 


\section{Tehran as a Case Study}

Iran's history is exceptionally complex, layered with dynasties and rulers whose influence extends way beyond the past and into modern-day Iran. Iran's ancient culture has a deep architectural tradition (Encyclopaedia Britannica Online, 2017) and if we look closely at Iranian architecture in past periods, we see the direct relationship between "technology" and architecture (Islami and Fotoohi, 2016). In a country whose culture produced unparalleled works of architecture in history, it is up to us to look seriously at contemporary architecture.

Contemporary Iranian architecture should be looking for the development of modern technological structures, and on the other hand, should be more cognisant of the traditional architecture and learning of its past. New technologies are still not well-known in the country and this has caused problems in creating a new style of Iranian architecture that would respond to human needs at present with respect to lingering past values and beliefs. An expanding economy, growing demand for contemporary lifestyles and booming investment in tourist infrastructure are combining to create new opportunities for architecture in this country. Thus, the trajectory of contemporary architecture in Iran is balanced between social demands and new technologies.

In common with many countries in the developing world, Iran is experiencing a rupture with the major traditions and achievements of the past (Diba, 1991). Since, the concept of interactive architecture is relatively new in the country, for its implementation, first, there is a need to identify the obstacles and limitations based on existing conditions and second, a meaningful set of guidelines need be provided that affect the future of architecture. In this regard, given that Iran as is a one of the most important developing countries that has some of the richest samples of architecture in history and a high speed of urban development in the new era, Tehran (social and political capital and largest city of Iran (Boroujerdi, 1974)), is an appropriate case study. In fact, Tehran is considered to be the link between Iran and other countries and thus, every change in Iranian architecture will first start from this city and then spread to other parts of Iran.

\section{RESEARCH METHODOLOGY}

\section{Limitations of Interactive Architecture in Tehran}

One of the requirements for the development of interactive architecture in today's world is the use of unique and unexplored methods in architecture, tailored to the needs of people. In this regard, identifying the factors that would be effective on the correct implementation of this architecture is one of the main goals of this research. Initially, recognising the obstacles and operational capabilities of this architecture is the key to success in the future.

Due to the main focus of the research on the future of interactive technologies in Tehran and to benefit from expert views, the Delphi method was used to collect the required information in this study. According to the new and innovative concept of interactive architecture in this city, purposeful sampling was applied and only experts who have sufficient expertise in both interactive architecture and contemporary Iranian architecture were selected to respond. The first group of experts consisted of five professors working in the field of digital and interactive 
architecture and Iranian contemporary architecture from the most prestigious universities in Iran. The second group was comprised 10 Doctor of Philosophy (PhD) students doing research in this field.

Thus, in the first stage, an open-ended questionnaire was designed and distributed among 15 defined experts to determine the main factors that can be more effective in the implementation of interactive architecture in Tehran. The result of this questionnaire was determining a set of default factors that would influence the adaptation of interactive architecture to the features of Iranian architecture. In the next stage, according to the experts' opinions, in order to assess the contemporary conditions of Iran more effectively and identity the limitations of implementing interactive architecture, these factors were classified in eight main groups (refer Figure 5) and finally, based on the previous steps, for each category, the parameters and factors that might be important and effective in understanding and identifying the strengths and weaknesses of that category were determined, and a final close-ended questionnaire was designed (refer Table 2) that consisted of a five-point Likert scale with five response options for respondents, where "Strongly Agree" = 5, "Agree" = 4, "Do Not Know" = 3, "Disagree" = 2 and "Strongly Disagree" = 1 . Given that the Likert scale is commonly used to measure attitudes, it was adopted to measure and analyse the importance level of each factor and to facilitate statistical analyses of the responses (Allen and Seaman, 2007; Croasmun and Ostrom, 2011; Norman, 2010). After collecting the responses in the questionnaire, they were converted to numerical scales to analyse the impact of the different factors in the future of Tehran's architecture. The data collected from the questionnaire survey were analysed according to a mean score and the value of "3" ( $\mu=3)$ was selected as the median for measuring the results.

$$
M S=\frac{\sum f^{*} S}{N} \quad 1 \leq M S \leq 5
$$

where,

$f=$ frequency of responses rating each main factor,

$s=$ score given to each main factor by the respondents and

$N=$ total number of responses concerning that factor (Priyadarshani, Karunasena and Jayasuriya, 2013; Tadayon, Jaafar and Nasri, 2012; Das and Emuze, 2017; Ojelabi, Oyeyipo and Afolabi, 2017). 
Table 2. The Applied Questionnaire in this Research

Category

Interactive Architecture in Tehran

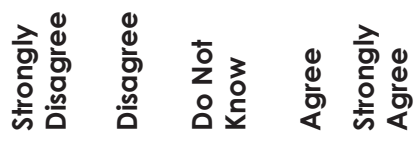

Environmental

Technological

Financial

Organisational

Social
1. Interactive projects respond to environmental conditions.

2. Interactive projects protect natural resources and the environment.

3. Interactive projects use natural/ recyclable materials in projects.

1. The latest technologies in Iran meet the requirements of interactive architecture.

2. Existing technical infrastructure in the country is responsible for implementing interactive projects.

3. Designers and architects have acquired expertise and capabilities needed to design interactive architecture.

1. Project implementation and maintenance cost in the life cycle of buildings are optimised.

2. Interest rates on domestic investment are consistent with the level of risk and return on investment.

3. Interactive architecture is more cost effective than traditional architecture.

4. Traineeship and specialist training costs are commensurate with the technical levels of projects.

1. Projects have evaluation and planning systems in order to achieve desired outcomes.

2. Projects have a scheduling system as the support tool for planning interactive projects.

1. Projects can increase participation between various groups of people.

2. Interactive architecture creates excitement, activity and vitality in society.

3. Interactive architecture can improve reliability and userfriendliness of buildings among users. 
Table 2. (continued)

Interactive Architecture in Tehran

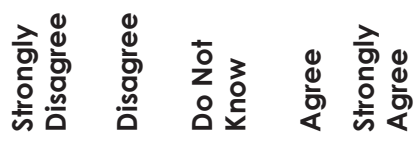

\begin{tabular}{|c|c|}
\hline Cultural & $\begin{array}{l}\text { 1. Interactive architecture has local } \\
\text { cultural identity. } \\
\text { 2. Interactive architecture can form } \\
\text { symbols of social values and } \\
\text { beliefs. } \\
\text { 3. Interactive architecture fosters } \\
\text { sense of belonging to place in } \\
\text { individuals. } \\
\text { 4. Interactive projects create } \\
\text { emotional relation between users } \\
\text { and architecture. }\end{array}$ \\
\hline Managerial & $\begin{array}{l}\text { 1. Architecture and urban planning } \\
\text { regulations support interactive } \\
\text { projects. } \\
\text { 2. Municipal policies control action } \\
\text { plans and improve project } \\
\text { management. }\end{array}$ \\
\hline Physical & $\begin{array}{l}\text { 1. In interactive architecture, spaces } \\
\text { are deployable. } \\
\text { 2. In interactive architecture, all } \\
\text { architectural structures exhibit } \\
\text { conceptual integrity. } \\
\text { 3. Interactive systems operate in } \\
\text { highly clear manner and are } \\
\text { consistently comprehensible for } \\
\text { all users. }\end{array}$ \\
\hline
\end{tabular}




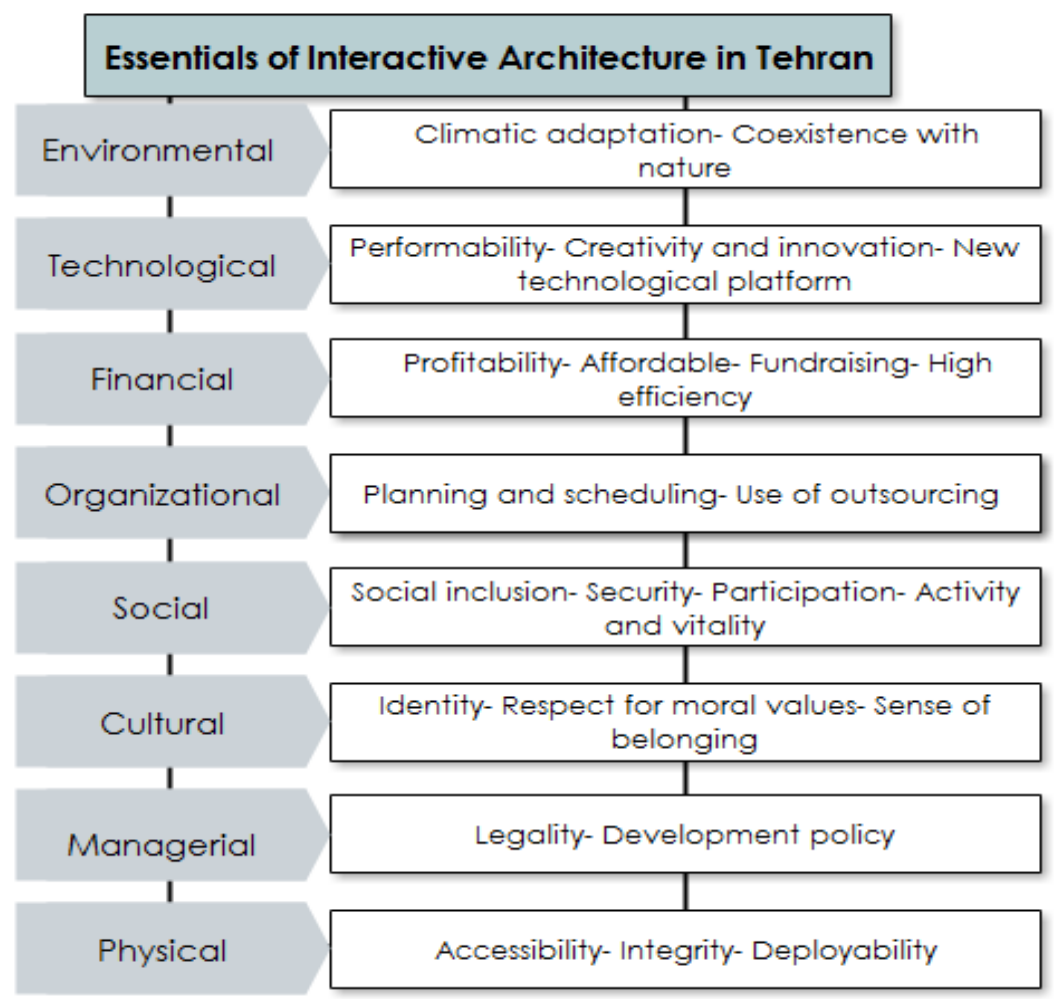

Figure 5. Essentials of Interactive Architecture in Iran

\section{ANALYSIS AND DISCUSSION}

After analysing the questionnaire and evaluating the responses given by the experts of interactive architecture, it was found that among these eight mentioned categories, the three main areas of technology, finance and culture, create the highest number of constraints for the implementation of real interactive architecture in Tehran (as in Figure 6).

In fact, the area of technology with an average of less than 3 in all sectors, the financial sphere with two averages above 4.5 and two averages below 3 , and finally all the earned averages being under 3 in the cultural field are indications of significant shortages in these areas. This is while, as can be seen in the following chart, the obtained averages in other areas indicate that the requirements and prerequisites for implementation of interactive architecture projects in Tehran are available and achievable. As a result, it can be stated that the three areas of technology, culture and economy are the main limiting factors of the implementation of interactive architecture in Tehran and the other factors presented in this research are its strengths. 


\section{Technological Limitations}

The autonomous operation of architecture and its ability to interact require the use of technology. Additionally, the process of development and deployment of interactive architecture can be catalysed or largely facilitated by employing various design instruments, novel materials and fabrication techniques (Jaskiewicz, 2013). Interactive architecture has risen as a consequence of new technological availability in the context of the built environment (Maia and Meyboom, 2015). The future of interactive architecture can best be predicted through examining the use of new technologies in other fields (Fox and Kemp, 2009). In a sense, the development process of interactive architecture can be facilitated and accelerated by the use of various design tools, new materials and innovative construction techniques.

The results of the analysis of the information in the diagram indicate that in the area of technology, all factors have a value less than 3 which means that in Tehran access to the latest technologies required for interactive architecture is not very feasible. The weakness of the technical infrastructure of the city is the next limiting factor in the implementation of interactive architecture. Also there is no skilled labour with the ability to design and build interactive systems.

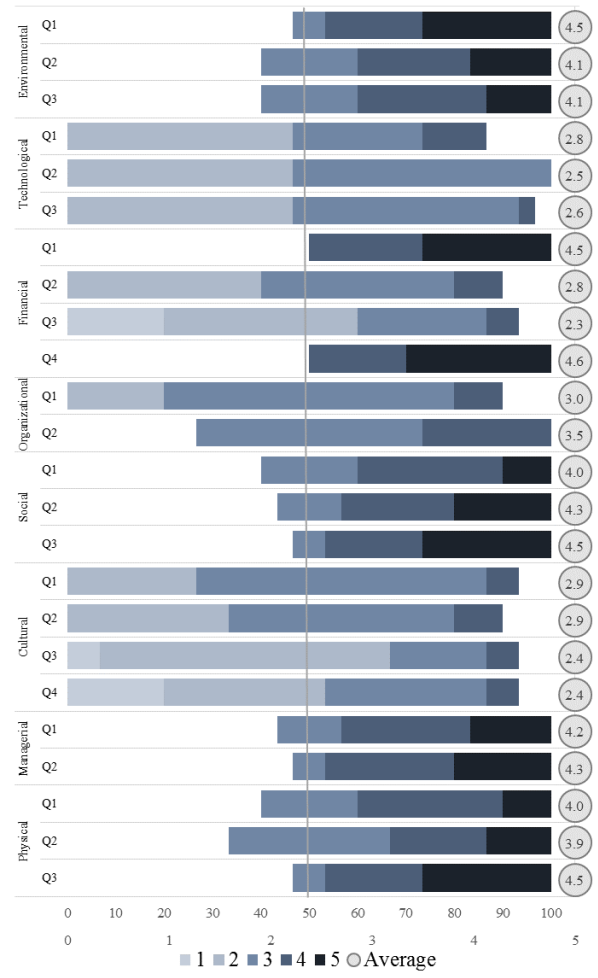

Note: Coloured version of this figure is available in the online edition of Journal of Construction in Developing Countries

Figure 6. The Results of Analysing the Questionnaire 
To put it more clearly, in Tehran, the poor coordination between manufacturing technologies in the construction industry and a new generation of architectural processes in the world, non-use of more advanced techniques and construction methods and tools, lack of effective studies on the limitations and abilities of technology can be some of the main factors deterring the country's progress. Meanwhile, the weakness of basic infrastructures in the field of technology can also limit the development of interactive architecture in the country. Furthermore, it can be argued that lack of information about interactive architecture as well as lack of experienced experts in this field has led to its slow progress in city (as shown in Figure 7).

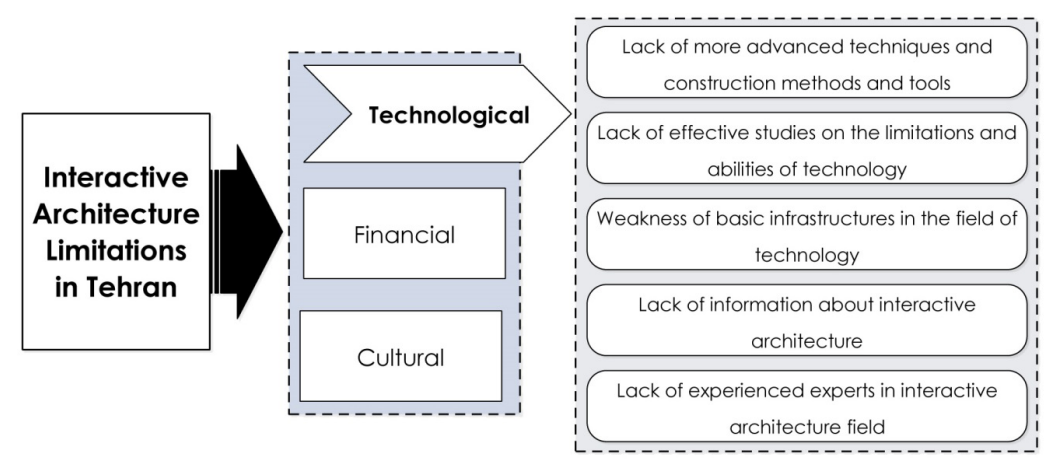

Figure 7. Technological Limitations of Interactive Architecture in Iran

\section{Financial Limitations}

The importance of taking measures to improve the performance of the construction industry has now been recognised in several countries at various levels of socioeconomic development (Loganathan et al., 2017). In the field of international management, issues concerning effective transfer of technology have been regarded as central to the field's mission. A great deal of emphasis has been placed on economic factors that affect transfer of technology (Contractor and Sagafi-Nejad, 1981; Arora, Fosfuri and Gambardella, 2004). On the other hand, in most of the developing countries, the construction industry has failed to play its expected role as an "engine of growth" by providing the basis for socio-economic development as even some of the rudimentary issues are still not being addressed adequately (Ofori, 2015). To put it simply, among the most important factors in construction industry development in any country are the financial issues related to building products.

Architects who want to experiment with interactive spaces, particularly on large, urban-scale projects, are often prevented from doing so because of the complexity, logistics or costs involved with such systems (Haque and Somlai-Fischer, 2005). It should be mentioned that, generally, whenever subjects such as responsive architecture appear, cost issues arise. Novelty of subject and insufficiency in the quantity of evidence, currently prevent concrete answers (Fotiadou, 2010). In other words, the issue of project financing has always been a main obstacle against the transforming of interactive architectural ideas into built projects because, basically, 
the new technology and mechanical systems used in these projects have high costs.

The results show that in relation to finance, the opinion of the majority of experts is that the estimated cost of project implementation and maintenance in the life cycle of buildings and traineeship and specialist training costs in accordance with the technical level of projects are high. Dynamic systems in interactive architecture require advanced technologies: these systems are more vulnerable and hence need constant repair and maintenance which will increase the building's lifecycle costs, a significant issue in Tehran. This is while the costs of traditional versus interactive architecture, at least on a short term basis, might still be significantly lower on the side of traditional architecture (Jaskiewicz, 2013).

Also, interest rates on domestic investment with regard to the level of risk and return on investment of interactive architecture in short-term projects are low compared to traditional architecture. Accordingly, in the implementation of interactive projects in Tehran, all groups involved in the project, from the designer to the investor and the contractor should consider the possible solutions for removing these constraints. Meanwhile, domestic and foreign investors, because of uncertainty in the profitability, high risk of investment and increased side costs of new and innovative projects, have little tendency to invest in them (as shown in Figure 8).

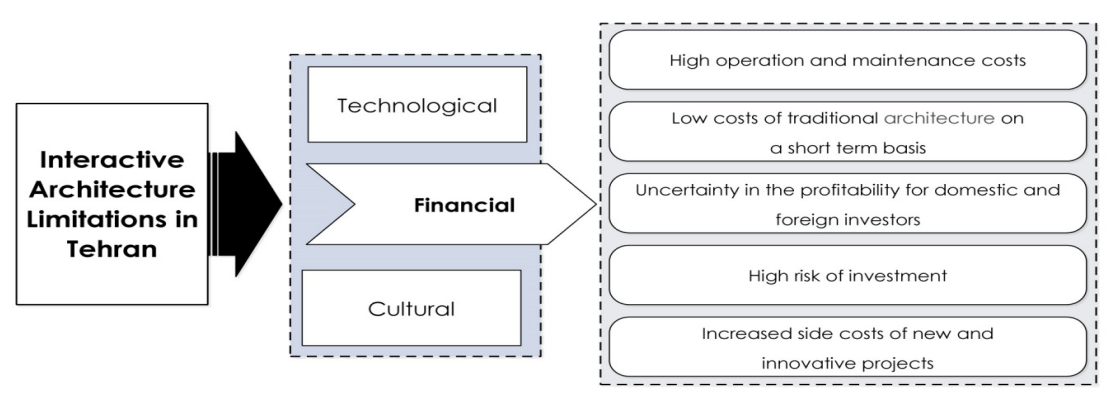

Figure 8. Financial Limitations of Interactive Architecture in Iran

\section{Cultural Limitations}

The notion of "culture" can be defined as the shared patterns of knowledge, beliefs, behaviours and values (Dawkins, 2016; Jiang, 2010). Thus, in analogical manner to the natural environment, human culture is continuously evolving (Pourjafar et al., 2014). The culture of human groups has never been a constant factor, with historical changes in culture occurring slowly as cultural patterns are passed on between generations and gradually transformed in the process (Jaskiewicz, 2013). To put simply, culture represents the identity of a society as provided in Figure 9.

Although the technology transfers among developed nations rely greatly on strategic orientations of transacting organisations, the transfers to developing countries depend on the compatibility of the cultures of the nations involved in such transactions (Kedia and Bhagat, 1988). A realistic appraisal of technological diffusion strategy should focus on the structure of preferences that exist in the recipient country at the time of transfer (Kedia and Bhagat, 1988; Karakosta, 2016). 
Traditional Iranian architecture grows within the community, and over time, adapts itself to cultural values and social, climatic and technological conditions.

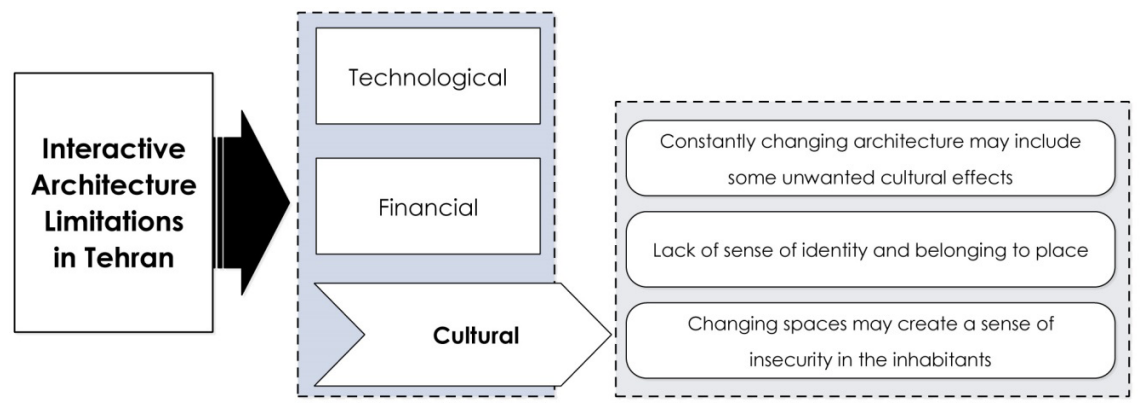

Figure 9. Cultural Limitations of Interactive Architecture in Iran

On this basis, Iranians have chosen an architecture that has more compatibility with social and cultural norms and their past experiences of space. The results of the data analysis show that all factors of interactive architecture implementation in the cultural field in Tehran have a value of less than 3. In fact, interactive architecture does not have a local cultural identity and cannot be a symbol of Iranian social values and beliefs. This fact dictates that people will not have a sense of belonging to interactive architecture, and the emotional relationship between users and architecture will not be created. These are the main limiting factors of the implementation of interactive architecture in the current conditions of Tehran.

Therefore, it can be argued that architecture with constantly changing processes in response to user needs may include some unwanted cultural and psychological effects. In fact, spaces with the ability to change in interactive architecture deprive people of the sense of identity and belonging to a particular place and may create a sense of insecurity in the inhabitants. As a result, interactive architecture in Tehran, due to its lack of harmony with the cultural values of the majority of people, will be limited in this regard.

\section{Opportunities of Interactive Architecture in Tehran}

Based on the results of the research, Tehran has the appropriate facilities in the environmental, organisational, social, managerial and physical fields to implement interactive architecture. Proper attention to, and use of these positive points will have an efficacious impact on the future of interactive architecture in this city and alleviate the existing restrictions. Investigating the relationship between the weaknesses and strengths shows that, interactive architecture is not limited to creating a building through the use of the most expensive and sophisticated technology but, it can be argued, providing the inhabitants' welfare in the built environment is the highest priority of an interactive architectural project. Meanwhile, this architecture experiences a special economic and technological feasibility, which makes it possible to engage wise operations, an opportunity for which it has been waiting so long. On the other hand, the ability of these systems to interact with the environment and residents can partly reduce their defects in the emotional and cultural fields. 
It can be verified that there are many ways to create interactive architecture that stem from technology, but technology is not the fundamental nature of interactive spaces (Amini et al., 2014). The success of interactive architecture is largely due to the creation of unique functional and organisational spaces that respond to different human needs and create flexibility, participation and creativity (Mohtashami, Mahdavinejad and Bemanian, 2016) in the inhabitants of the built environment. Based on the conceptual viewpoints of the experts interviewed in this study, it can be stated that interactive environments provide many opportunities for contemporary and future Iranian architecture. Given that interactive architecture has the ability of multipurpose optimisation for spatial reorganisation, it can create flexibility in building spaces and provide wellbeing and satisfaction through change in environmental affordances and respond to the natural needs of inhabitants.

In the same vein, interactive architecture can lead to a significant reduction in the use of vital resources such as materials, energy, time and space. Continuous adaptation between humans, buildings and the natural environment guarantees sustainability in built environments and increases the useful life of buildings in the city resulting in the optimisation of energy consumption which can reduce urban energy costs. Other advantages of this architecture in Tehran can be the expansion of the scope of residential performance in space, the strengthening of public participation between individuals in buildings (Mahdavinejad and Amini, 2011), the improvement of social relationships and security (Bemanian and Amini, 2017) and finally, change in architectural patterns. It is not claimed that all of the above opportunities are inherent in interactive architecture, but this architecture can gradually develop its behaviour and meet these goals (as shown in Figure 10).

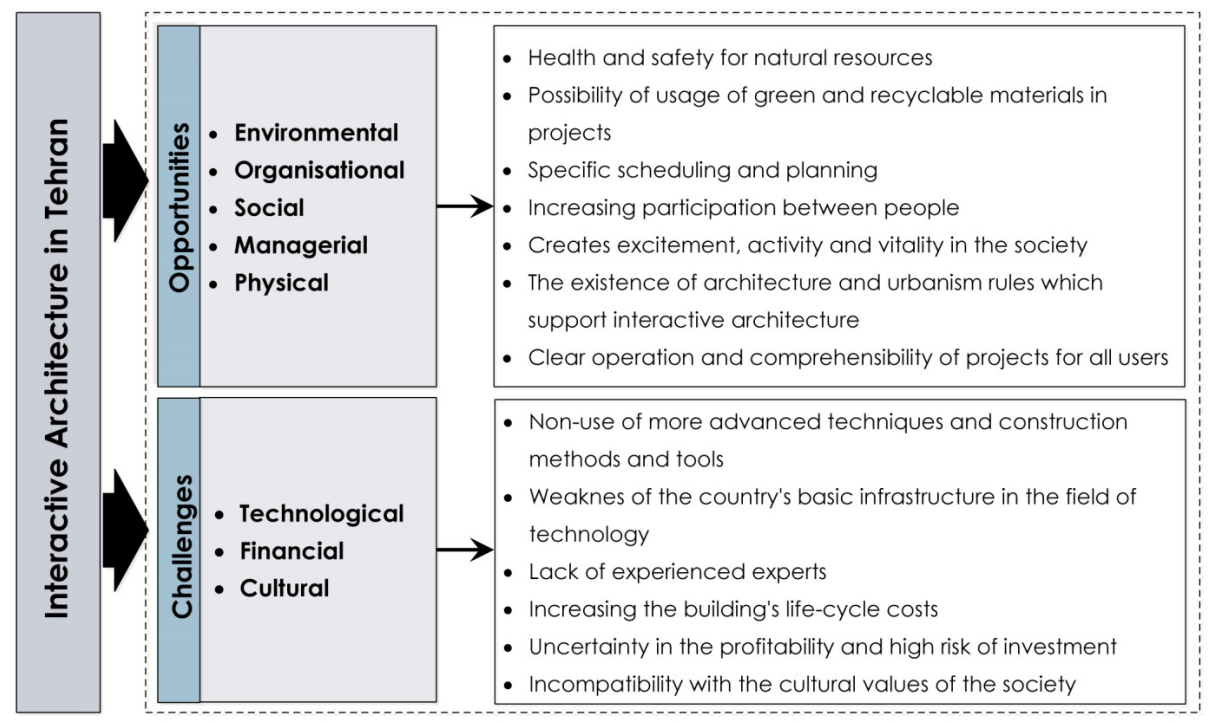

Figure 10. Challenges and Opportunities of Interactive Architecture in Iran 


\section{CONCLUSION}

The main focus of the paper is to show that the success of interactive architecture in developing countries, to a large extent, depends on the extent to which these countries benefit from the facilities and capabilities of this dynamic, flexible and constantly changing architecture which can be a good alternative to traditional and static architecture. In this regard, recognising and trying to resolve the limitations and obstacles and creating appropriate national and international standards in the construction industry will improve the present and future conditions of interactive architecture in these countries.

The results from this study show that technological deficiencies in the country's infrastructure, inaccessibility to the latest technology and a lack of experience and expertise are the major challenges. In the financial sphere, interactive project costs and their investment risks are high; hence, there is little willingness to invest. Finally, in the field of culture, in the present situation, interactive architecture does not have the ability to respond to the traditional cultural needs and values of Iranian society. Additionally, the results show that other areas affecting interactive architecture in Tehran have a status comparable with that of developed countries and therefore, these areas do not pose any specific problems.

Hence, developing countries which move from traditional architecture to interactive architecture should try to develop and optimise existing technologies in the country to achieve this architecture's goals, until they can adopt local and optimal methods and strategies to provide the cultural and emotional needs of the users in the buildings and ultimately the developmental process of this architecture is accelerated.

Meanwhile, it should be noted that in developing countries, religious beliefs and culture are still powerful factors in determining the use of technology and in economic growth; in these societies, people believe that economy and technology are instruments for the promotion of the cultural values of the people and should never be considered as a goal in them. Accordingly, the results of the research show that the materialisation of interactive architecture in developing countries might be much more different than it is in developed countries.

In other words, it is the cultural issue that determines the feasibility of interactive architecture rather than other elements. In such countries key elements such as "technology" should be adopted with consideration of the cultural context. Technology is largely influenced by culture and in addition to the need for economic, social, managerial and other infrastructural elements to implement interactive architecture in developing countries, it is necessary to establish a cultural foundation to create a flexible relationship between all the factors.

\section{ACKNOWLEDGEMENTS}

This article is derived from the doctoral thesis of the first author in Tarbiat Modares University under the title of Interactive Architecture Paradigm: Mechanisms for Interaction between New Technologies and Iranian Contemporary Architecture. The authors would like to thank all professors and doctoral students in the field of interactive architecture in Iran who participated in the survey and supported the work. 


\section{REFERENCES}

Abrahamson, M. (2009). Reconsidering Reyner Banham. Available at: https:// www. criticundertheinfluence.wordpress.com/2009/03/30/reconsidering-reynerbanham [Accessed on 17 August 2017].

Abramovic, V. and Glynn, R. (2018). Edge of Chaos. London: Interactive Architecture Lab. Available at: http://www.interactivearchitecture.org/ lab-projects/edge-of-chaos [Accessed on 12April 2018].

Allen, I.E. and Seaman, C.A. (2007). Likert scales and data analyses. Quality Progress, 40(7): 64.

Amini, M., Mahdavinejad, M., Bemanian, M.R. and Varzaneh, E.H. (2014). Developing a new paradigm for performance of educating city theory in advanced technology mega-cities, case: Tehran, Iran. Journal of Architecture and Urbanism, 38(2): 130-141. https://doi.org/10.3846/20297955.2014.925629.

Arora, A., Fosfuri, A. and Gambardella, A. (2004). Markets for Technology: The Economics of Innovation and Corporate Strategy. Cambridge, MA: MIT Press.

Bani Masoud, A. (2011). Contemporary Architecture of Iran. Tehran: Honar-e Memari-ye Gharn.

Beesley, P. (2006). Responsive Architectures: Subtle Technologies 2006. Ontario, Canada: Riverside Architectural Press.

Bemanian, M.R. and Amini, M. (2017). Social Architecture: Iranian House. Tehran: Avaloakhar.

Boroujerdi, M. (1974). The centrality of Tehran in Iranian sociopolitical life. Economic Analysis, 10: 60-70.

Bullivant, L. (2005). 4dspace: Interactive Architecture (Architectural Design). Chichester, England: John Wiley and Sons.

Butcher, D. (2006). Shape-shifting structures adapt to environment. Thomas Industry Update, 13 September. Available at: https://news.thomasnet.com/ $\mathrm{imt} / 2006 / 09 / 13 /$ shapeshifting_responsive_smart_buildings_architecture_ adapt_environment [Accessed on 13 September 2016].

Camile, A.S. (2005). Liquid architectures: Marcos Novak's territory of information. MA diss. University of Brasilia.

Chen, X. (2015). Interactive pavillions: Responsive transformation of structure systems. Architecture Thesis Prep, 285.

Contractor, F.J. and Sagafi-Nejad, T. (1981). International technology transfer: Major issues and policy responses. Journal of International Business Studies, 12(2): 113-135. https://doi.org/10.1057/palgrave.jibs.8490582.

Croasmun, J.T. and Ostrom, L. (2011). Using Likert-type scales in the social sciences. Journal of Adult Education, 40(1): 19-22.

Das, D.K. and Emuze, F. (2017). A dynamic model of contractor-induced delays in India. Journal of Construction in Developing Countries, 22(1): 21-39.

Dawkins, R. (2016). The Selfish Gene. Oxford: Oxford University Press.

Diba, D. (1991). Regional report: Iran and contemporary architecture. In MIMAR 38: Architecture in Development. London: Concept Media Ltd.

Drumm, P. (2012). Cosmic quilt. The Architects Newspaper, 26 October. Available at: https://archpaper.com/2012/10/the-principals-make-waves-in-interactivearchitecture-with-cosmic-quilt [Accessed on 17 December 2017]. 
Edmondson, J.H. (2001). Impact of physical technology on architecture. In A. Chandrakasan, W.J. Bowhill and F. Fox (eds.), Design of High-Performance Microprocessor Circuits. New York: Wiley-Institute of Electrical and Electronics Engineers (IEEE) Press, 3.

Encyclopaedia Britannica Online. (2017). Available at: https://www.britannica. com/place/Iran/The-arts\#ref783973 [Accessed on 20 June 2017].

Fotiadou, A. (2010). Computing towards responsive architecture: Energy based simulation software for responsive structures. In Future Cities: 28th eCAADe Conference Proceedings. Zurich: Eidgenossische Technische Hochschule (ETH) Zurich, 507-513.

Fox, M. (2016). Interactive Architecture: Adaptive World. New York: Princeton Architectural Press.

Fox, M. and Kemp, M. (2009). Interactive Architecture. New York: Princeton Architectural Press.

Ghobadian, V. (2013). Styles and Concepts in Iranian Contemporary Architecture. Tehran: Elme Meamar Publication.

Greenfield, A. (2010). Everyware: The Dawning Age of Ubiquitous Computing. Upper Saddle River, NJ: Pearson Education.

Haque, U. (2007). Distinguishing concepts: Lexicons of interactive art and architecture. Architectural Design, 77(4): 24-31. https://doi.org/10.1002/ ad.484.

- (2006). Architecture, interaction, systems. Arquitetura and Urbanismo, 149: $1-5$.

Haque, U. and Somlai-Fischer, A. (2005). Low Tech Sensors and Actuators for Artists and Architects. Liverpool: Foundation for Art and Creative Technology (FACT).

Hosale, M. and Kievid, C. (2009). Interactive wall. Hyperbody Archive. Delft, The Netherlands: Delft University of Technology. Available at: http://www. hyperbody.nl/research/projects/interactivewall/ [Accessed on 17 December 2017].

Islami, S.G. and Fotoohi, E. (2016). A look at Iranian architecture and assessing its features and technological aspects. Engineering Science and Technology: An International Journal, 6(1): 42-50.

Jaskiewicz, T. (2013). Towards a methodology for complex adaptive interactive architecture. PhD diss. Delft University of Technology (TU Delft).

Jaskiewicz, T., Aprile, W.A. and van der Helm, A. (2010). Creative approach to the design and prototyping of experimental smart spaces, case studies from the interactive environments minor. Smart Spaces and Next Generation Wired/ Wireless Networking. Berlin, Heidelberg: Springer.

Jiang, D. (2010). A study of the teaching of culture in college English. Journal of Language Teaching and Research, 1 (5): 735-737.

Karakosta, C. (2016). A holistic approach for addressing the issue of effective technology transfer in the frame of climate change. Energies, 9: 503. https:// doi.org/10.3390/en9070503.

Kedia, B.L. and Bhagat, R.S. (1988). Cultural constraints on transfer of technology across nations: Implications for research in international and comparative management. Academy of Management Review, 13(4): 559-571. https:// doi.org/10.5465/amr.1988.4307424.

Keniger, L.E., Gaston, K.J., Irvine, K.N. and Fuller, R.A. (2013). What are the benefits of interacting with nature? International Journal of Environmental Research and Public Health, 10(3): 913-935. https://doi.org/10.3390/ijerph10030913. 
Kiani, M., Behjou, A. and Tehrani, N.R. (2016). Spatial continuity in contemporary Iranian architecture. Naqshejahan: Basic Studies and New Technologies of Architecture and Planning, 5(3): 52-67.

Krakowsky, T. (2008). Interactive architecture. segdDESIGN, No. 22.

Kronenburg, R. (2003). Transportable environments: Experiment, research and design innovation. In R.H. Kronenburg, J. Lim and Y.C. Wong (eds.), Transportable Environments 2. Abingdon, UK and New York, USA: Spon Press, 51-56.

Lee, H. (1983). Conversation Theory: Applications in Education and Epistemology; Pask, G. London: Kogan Page Ltd.

Lénárd, I. and Oosterhuis, K. (2006). Digital Pavilion. 's-Gravenzande, The Netherlands: The Innovation Studio (ONL). Available at: http://onl.eu/projects/digitalpavilion [Accessed on 3 April 2018].

Loganathan, S., Srinath, P., Kumaraswamy, M., Kalidindi, S. and Varghese, K. (2017). Identifying and addressing critical issues in the Indian construction industry: Perspectives of large building construction clients. Journal of Construction in Developing Countries, 22(Supp. 1): 121-144. https://doi.org/10.21315/ jcdc2017.22.supp1.7.

Mahdavinejad, M. and Amini, M. (2011). Public participation for sustainable urban planning in case of Iran. Procedia Engineering, 21: 405-413. https://doi. org/10.1016/j.proeng.2011.11.2032.

Mahdavinejad, M., Rafsanjani, L. and Karimi, M. (2013). Challenges and opportunities regarding adoption of clean energy technology in developing countries, in case of Iran. International Journal of Smart Grid and Clean Energy, 2(2): 283288. https://doi.org/10.12720/sgce.2.2.283-288.

Mahdavinejad, M., Zia, A., Larki, A.N., Ghanavati, S. and Elmi, N. (2014). Dilemma of green and pseudo green architecture based on LEED norms in case of developing countries. International Journal of Sustainable Built Environment, 3(2): 235-246. https://doi.org/10.1016/j.jijsbe.2014.06.003.

Maia, S.C. and Meyboom, A. (2015). Interrogating interactive and responsive architecture: The quest of a technological solution looking for an architectural problem. Proceedings: International Conference on Computer-Aided Architectural Design Futures. Berlin, Heidelberg: Springer, 93-112.

Meagher, M. (2015). Designing for change: The poetic potential of responsive architecture. Frontiers of Architectural Research, 4(2): 159-165. https://doi. org/10.1016/j.foar.2015.03.002.

Mirmoghtadaee, M. (2009). Process of housing transformation in Iran. Journal of Construction in Developing Countries, 14(1): 69-80.

Mohtashami, N., Mahdavinejad, M. and Bemanian, M. (2016). Contribution of city prosperity to decisions on healthy building design: A case study of Tehran. Frontiers of Architectural Research, 5(3): 319-331. https://doi.org/10.1016/j. foar.2016.06.001.

Norman, G. (2010). Likert scales, levels of measurement and the "laws" of statistics. Advances in Health Sciences Education, 15(5): 625-632. https://doi. org/10.1007/s10459-010-9222-y.

Ofori, G. (2015). Nature of the construction industry, its needs and its development: A review of four decades of research. Journal of Construction in Developing Countries, 20(2): 115-135. 
Ojelabi, R.A., Oyeyipo, O.O. and Afolabi, A. (2017). Built environment professionals' perceptions of the effectiveness of building control measures in Lagos State. Journal of Construction in Developing Countries, 22(1): 41-54. https://doi. org/10.21315/jcdc2017.22.1.3.

Oosterhuis, K. (2013). Digital in Architecture/Methodologies and Paradigms. 's-Gravenzande, The Netherlands: ONL. Available at: http://www.onl.eu/ news/kas-oosterhuis-lectures-canadian-centre-architecture [Accessed on 16 April 2017].

Oosterhuis, K. and Lénárd, I. (2007). ILITE. 's-Gravenzande, The Netherlands: ONL. Available at: http://onl.eu/projects/ilite [Accessed on 3 April 2018].

Parsaee, M., Motealleh, P. and Parva, M. (2016). Interactive architectural approach (interactive architecture): An effective and adaptive process for architectural design. HBRC Journal, 12(3): 327-336. https://doi.org/10.1016/j. hbrcj.2015.01.001.

Peters, B. (2013). How technology is changing architecture. VICE, 12 April. Available at: https://creators.vice.com/en_uk/article/mgpqvv/how-technology-ischanging-architecture.

Pourjafar, M., Amini, M., Varzaneh, E.H. and Mahdavinejad, M. (2014). Role of bazaars as a unifying factor in traditional cities of Iran: The Isfahan bazaar. Frontiers of Architectural Research, 3(1): 10-19. https://doi.org/10.1016/j. foar.2013.11.001.

Prelovsek, M. (2017). Technologies for Interactive Architecture. Ljubljana, Slovenia: VISIBLE.

Priyadarshani, K., Karunasena, G. and Jayasuriya, S. (2013). Construction safety assessment framework for developing countries: A case study of Sri Lanka. Journal of Construction in Developing Countries, 18(1): 33-51.

Riley, T. (2002). The Changing of the Avant-Garde: Visionary Architectural Drawings from the Howard Gilman Collection. New York: The Museum of Modern Art.

Rostow, W.W. (1984). Development: The political economy of the Marshallian long period. In P.T. Baver, G.M. Meier and D. Seers (eds.), Pioneers in Development. Washington DC: The World Bank, 229-261.

Tadayon, M., Jaafar, M. and Nasri, E. (2012). An assessment of risk identification in large construction projects in Iran. Journal of Construction in Developing Countries, 17(Supp. 1): 57-69.

Terzidis, K. (2003). Expressive Form: A Conceptual Approach to Computational Design. London: Taylor and Francis. 